\title{
DOOR OPENING ANALYSIS OF WIND TURBINE STEEL TUBULAR TOWER
}

\author{
Ajay R. Vaghela ${ }^{1}$, G.S.Doiphode ${ }^{2}$ \\ ${ }^{1}$ ME Student, Applied Mechanics Department, Faculty of Technology and Engineering, Gujarat, India \\ ${ }^{2}$ Assistant Professor, Applied Mechanics Department, Faculty of Technology and Engineering, Gujarat, India
}

\begin{abstract}
The main objective is to investigate the stresses around the door opening for the load cases that creates highest stresses. The influence of different material thicknesses at the tower lower parts. It investigates the lower tower section which includes the door opening which is used for service and maintenance inside the tower. The loading of the tower generates the stresses around the door opening and these stresses will analyze for static analysis using the FEM software ANSYS 14.5. As there is more probability of having crack near the door opening. To investigate the influence on the stress level and ultimate load of the tower, the tower shell thickness around the door opening varied in simulation. There are total six models prepared in the paper among which two models are prepared with uniform thickness of $38 \mathrm{~mm}$, two models are prepared with $38 \mathrm{~mm}$ thickness at the base and $15 \mathrm{~mm}$ at the top and two models are prepared with $70 \mathrm{~mm}$ thickness at the base and $15 \mathrm{~mm}$ at the top. For every condition there are two wind cases considered in first direction of wind is considered on the side of door opening and in second case wind direction is considered on the opposite side of the door opening. After got the values for the stresses fracture analysis and fatigue analysis of the section near the door opening have carried out. We uses steel of grade 355 (S355) and wind data has calculated according to the IS 875 part 3.
\end{abstract}

Keywords: door opening, ANSYS, Shell thickness, and Wind turbine tower

\section{INTRODUCTION}

In 2012, despite a slowing global economy, India's electricity demand continued to rise. Electricity shortages are common, and over $40 \%$ of the population has no access to modern energy services. India's electricity demand is projected to more than triple between 2005 and 2030. In the recently released National electricity Plan (2012) the Central electricity Authority projected the need for 350-360 GW of total generation capacity by 2022 . Despite major capacity additions over recent decades, power supply struggles to keep up with demand [1].

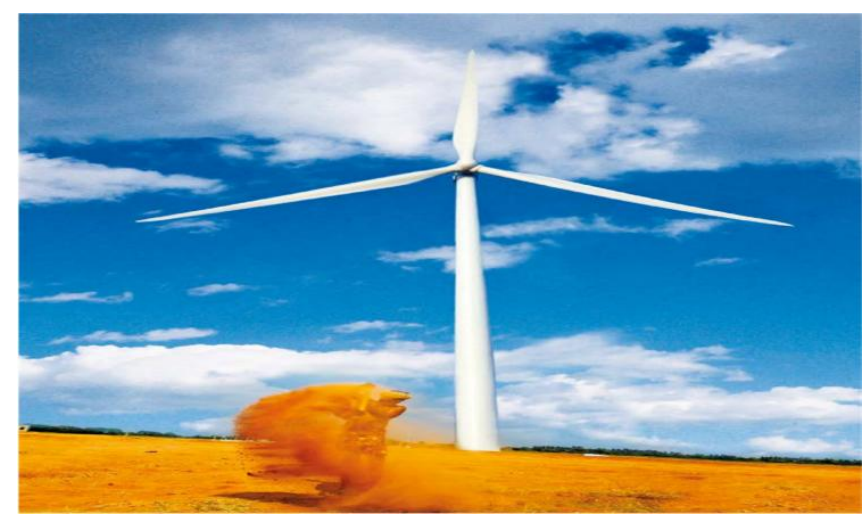

Fig -1: Wind turbine in India [1]

India had another record year of new wind energy installations between January and December 2011, installing more than $3 \mathrm{GW}$ of new capacity for the first time to reach a total of 16,084 MW. As of march 2012, renewable energy accounted for 12.2 percent of total installed capacity, up from 2 percent in 1995. Wind power accounts for about 70 percent of this installed capacity. By the end of August 2012, wind power installations in India had reached 17.9 GW.

Under the New Policies Scenario of the World energy outlook (2011), total power capacity in India would reach $779 \mathrm{GW}$ in 2035. To reach $779 \mathrm{GW}$ in 2035, without a significant role for renewables. During fiscal year 20112012 wind energy alone delivered over $3 \mathrm{GW}$ to India's new installed capacity, accounting for over 16.5 percent of total new installed capacity.

\subsection{Preliminary Remarks}

To extract energy from wind, Wind turbines emerged as one of the most efficient ways of converting the kinetic energy in wind into mechanical power. Many energy providers invested in research and development of wind turbines. Now a days wind turbines are installed in many countries.

Steel towers for multi megawatt turbine consist usually of several conical steel segments which are welded together to sections. These sections are connected by bolted flange connection. A typical feature of these towers is the presence of a manhole cut-out near the bottom, serving purposes of accessibility into the tower for maintenance of the electrical and mechanical equipment.

As stated in Part 1-6 of EN1993, a hole in a shell of revolution (Cylindrical or conical) with radius $r$ and thickness $t$ may be neglected in the modelling provided that 
its largest dimension is smaller than $0.5 \sqrt{ } \mathrm{rt}$.Typical manholes of wind turbine towers are significantly Larger and lower significantly the tower strength including stress concentrations and increased danger of local buckling. During the last decade many wind turbine damage occurs due to the structural failure of wind turbine towers. Majority of these failures are caused by the strong wind striking the structure or wind induced vibrations. Others are caused by high stresses and buckling loads [2].

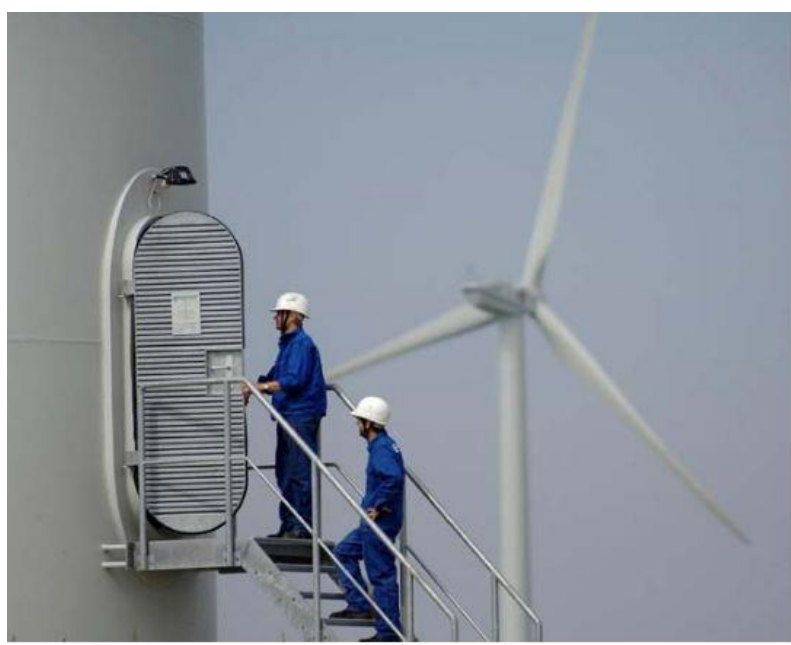

Fig -2: Typical door opening in tower

Wind turbine towers are designed as thin-walled structure having thickness very less than the diameter. In order to reduce the weight of tower, the vertical dimensions of the tower is relatively large compared to its horizontal dimensions. This slender nature of wind turbine tower makes it more sensitive to wind loading. There are many different configurations in which wind turbine support structure is designed. It common practice to design wind turbine towers as taper tubular column since they are given more stability to tower against the wind Loads and to save the material.

\section{METHODOLOGY}

\subsection{Basic Assumptions}

1) The basic structural model of the tower is represented by an equivalent long, slender cantilever beam built from segments (modules) having different but uniform cross- sectional properties. The tower is cantilevered to the ground, and is carrying a concentrated mass at its free end approximating the inertia properties of the nacelle/rotor unit. This mass is assumed to be rigidly attached to the tower top.

2) Material of construction is linearly elastic, isotropic and homogeneous. The tower has a thin-walled circular cross-section.

3) The Euler-Bernoulli beam theory is used for predicting deflections. Secondary effects such as axial and shear deformations, and rotary inertia are neglected.
4) Distributed aerodynamic loads are restricted to profile drag forces. A two-dimensional (2D) steady flow model is assumed.

5) Nonstructural mass will not be optimized in the design process. Its distribution along the tower height will be taken equal to some fraction of the structural mass distribution.

6) Structural analysis is confined only to the case of flapping motion (i.e. Bending perpendicular to the plane of rotor disk).

7) Under any load combination (including any load safety factors), the material of the load bearing structural elements of the tower should remain in the linear elastic region of its stress-strain diagram i.e. no plastic deformation has occurred.

\subsection{Description of the Structure}

As the name of the paper suggest we have taken tubular tower in our study right throughout. We have model three different wind turbine towers all for 3.0 MW. They are designed as tapered tubular tower with increasing diameter towards the base. The $\mathrm{T}$ thickness varies in all the three cases.

The dimensions of 1 st tower are at base the outer diameter is $4.5 \mathrm{~m}$ and at the top the outer diameter is $3.8 \mathrm{~m}$. the thickness of the tower is constant throughout and it is 38 $\mathrm{mm}$. The height of the tower is $100 \mathrm{~m}$. The dimensions of 2nd tower are at base the outer diameter is $4.5 \mathrm{~m}$ and at the top the outer diameter is $3.8 \mathrm{~m}$. the thickness at the base is $38 \mathrm{~mm}$ and at the top is $15 \mathrm{~mm}$. The height of the tower is $100 \mathrm{~m}$. The dimensions of 3rd tower are at base the outer diameter is $4.5 \mathrm{~m}$ and at the top the outer diameter is $3.8 \mathrm{~m}$. the thickness of the tower at base is $70 \mathrm{~mm}$ and at the top is $15 \mathrm{~mm}$. The height of the tower is $100 \mathrm{~m}$. (table 1).

The typical door opening dimension is also seen un the figure 3 .

\subsection{Material Used}

S355 is most commonly used material in wind turbine towers. S355 Grade 50 is considered a "workhorse" grade and is widely used in many applications.

S355 is a high strength, low alloy steel that finds its best application where there is need for more strength per unit of weight. Less of this material is needed to fulfil given strength requirements than is necessary with regular carbon steels.

In addition, S355 is noted for its increased resistance to atmospheric corrosion. Particularly Grade 50 contains more alloying elements than plain carbon steel and thus is somewhat more difficult to form. Grade 50 is more difficult to cold work, but can be successfully bent or shaped but requires more force than plain carbon steel.

It is commonly used in structural applications, heavy construction equipment, building structures, heavy duty anchoring systems, truck frames, poles, liners, conveyors, 
boom sections, structural steel shapes, and applications that require high strength per weight ratio.

Table -1: Dimension of the tower

\begin{tabular}{|l|l|l|l|}
\hline & $\begin{array}{l}\text { Tower } \\
\text { with } \\
\text { uniform } \\
\text { thickness }\end{array}$ & $\begin{array}{l}\text { Tower } \\
\text { with } \\
\text { usual } \\
\text { thickness }\end{array}$ & $\begin{array}{l}\text { Tower } \\
\text { with } \\
\text { higher } \\
\text { thickness }\end{array}$ \\
\hline $\begin{array}{l}\text { Outer } \\
\text { diameter } \\
\text { at base }\end{array}$ & $4.5 \mathrm{~m}$ & $4.5 \mathrm{~m}$ & $4.5 \mathrm{~m}$ \\
\hline $\begin{array}{l}\text { Inner } \\
\text { diameter } \\
\text { at base }\end{array}$ & $4.462 \mathrm{~m}$ & $4.462 \mathrm{~m}$ & $4.430 \mathrm{~m}$ \\
\hline $\begin{array}{l}\text { Outer } \\
\text { diameter } \\
\text { at top }\end{array}$ & $3.8 \mathrm{~m}$ & $3.8 \mathrm{~m}$ & $3.8 \mathrm{~m}$ \\
\hline $\begin{array}{l}\text { Inner } \\
\text { diameter } \\
\text { at top }\end{array}$ & $3.762 \mathrm{~m}$ & $3.785 \mathrm{~m}$ & $3.785 \mathrm{~m}$ \\
\hline $\begin{array}{l}\text { Thickness } \\
\text { at base }\end{array}$ & $38 \mathrm{~mm}$ & $38 \mathrm{~mm}$ & $70 \mathrm{~mm}$ \\
\hline $\begin{array}{l}\text { Thickness } \\
\text { at top }\end{array}$ & $38 \mathrm{~mm}$ & $15 \mathrm{~mm}$ & $15 \mathrm{~mm}$ \\
\hline height & $100 \mathrm{~m}$ & $100 \mathrm{~m}$ & $100 \mathrm{~m}$ \\
\hline
\end{tabular}
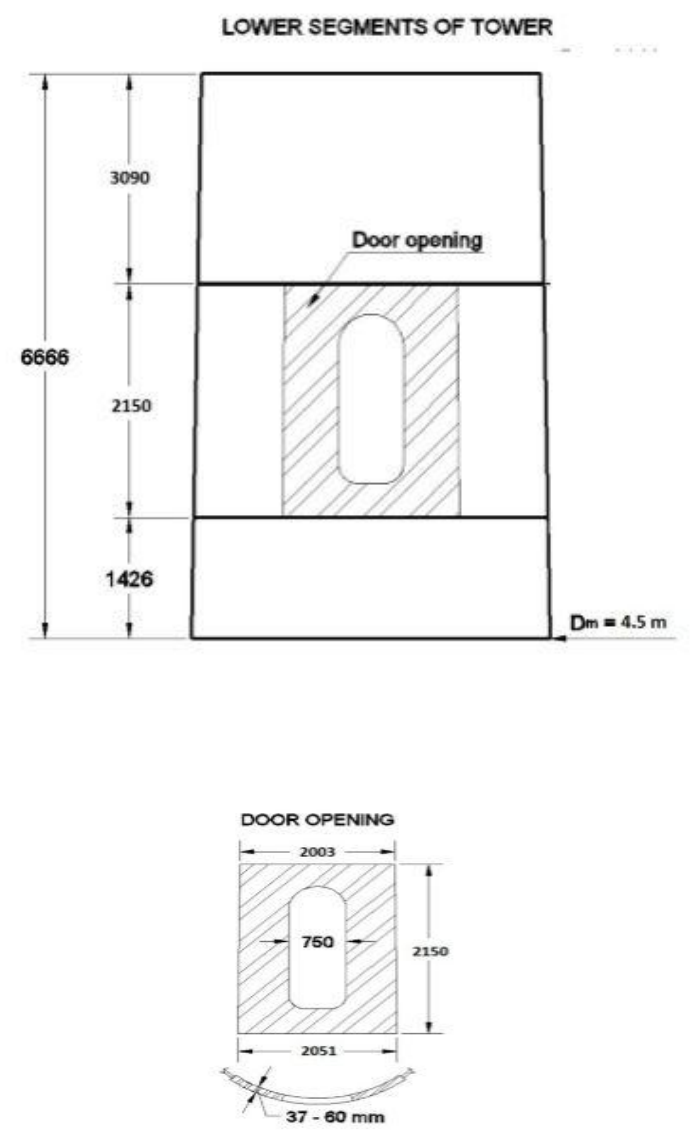

Fig -3: Door opening dimension

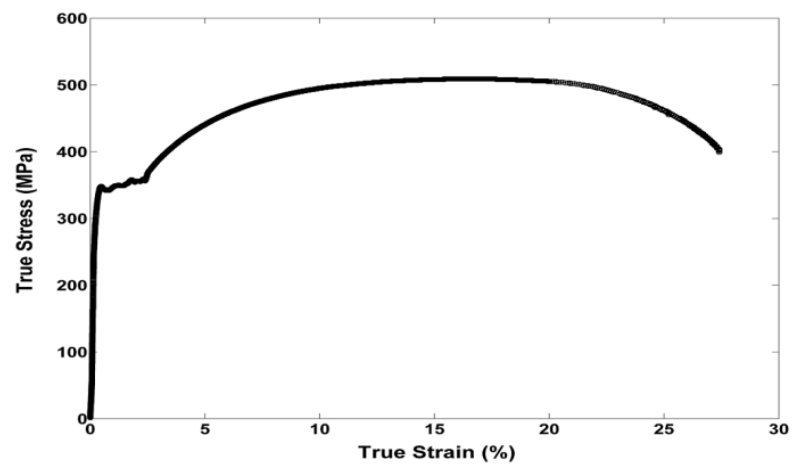

Fig -4: Stress strain curve for S355

\subsection{Load Calculation}

\subsubsection{Basic Wind Speed}

Basic wind speed is based on peak gust velocity averaged over a short time interval of about 3 seconds and corresponds to mean heights above ground level in an open terrain. Basic wind speed for some important cities/towns is also given in IS Code [3].

\subsubsection{Design Wind Speed}

The basic wind speed ( $\mathrm{Vb}$ ) for any site shall be obtained from IS code [3] and shall be modified to include the following effects to get design wind velocity at any height (Vz) for the chosen structure:

a) Risk level;

b) Terrain roughness, height and size of structure; and

c) Local topography.

It can be mathematically expressed as follows:

$$
\mathrm{Vz}=\mathrm{Vb} \mathrm{k} 1 \mathrm{k} 2 \mathrm{k} 3
$$

Where,

$\mathrm{Vz}=$ design wind speed at any height $\mathrm{z}$ in $\mathrm{m} / \mathrm{s}$; $\mathrm{k} 1$ = probability factor (risk coefficient);

$\mathrm{k} 2$ = terrain, height and structure size factor and $\mathrm{k} 3$ = topography factor.

\subsubsection{Design Wind Pressure $(\mathrm{Pz})$}

The design wind pressure at any height above mean ground level shall be obtained by the following relationship between wind pressure and wind velocity:

$$
\mathrm{Pz}=0.6 \mathrm{Vz}^{2}
$$

Where,

$\mathrm{Pz}=$ design wind pressure in $\mathrm{N} / \mathrm{m}^{2}$ at height $\mathrm{z}$, and $\mathrm{Vz}=$ design wind velocity in $\mathrm{m} / \mathrm{s}$ at height $\mathrm{Z}$.

\subsubsection{Wind Force $(\mathrm{Fz})$}

When calculating the wind load on individual structural elements such as roofs and walls, and individual cladding units and their fittings, it is essential to take account of the pressure difference between opposite faces of such elements 
or units. For clad structures, it is, therefore, necessary to know the internal pressure as well as the external pressure. Then the wind load, F, acting in a direction normal to the individual structural element or cladding unit is:

$$
\mathrm{F}=(\mathrm{cpe}-\mathrm{cpi}) \mathrm{APz}
$$

Where,

cpe $=0.95$

The wind force comes out as $670.250 \mathrm{KN}$ and wind pressure comes out as $1915 \mathrm{~N} / \mathrm{m}^{2}$ with the design wind speed as $56.47 \mathrm{~m} / \mathrm{s}$ and basic speed $44 \mathrm{~m} / \mathrm{s}$ for Vadodara. Also $\mathrm{k}_{1}$ is taken as 1.07 for tower with design life 100 years, $k_{2}$ is taken as 1.20 for $100 \mathrm{~m}$ height for terrain category- 1 and for class-c and $\mathrm{k}_{3}$ is taken as 1.0 .

Loading is considered as 0 based cyclic loading.

\section{FINITE ELEMENT ANALYSIS}

The static analysis is performed by using three-dimensional (3D) finite element models created with Finite Element Analysis (FEA) program ANSYS. The dimensions of the model are the same as shown in table 1. Fig. 5 shows the tapered cylindrical tower geometry including the diameter, the thickness, and the overall length of typical 3.0 MW wind turbine tower.

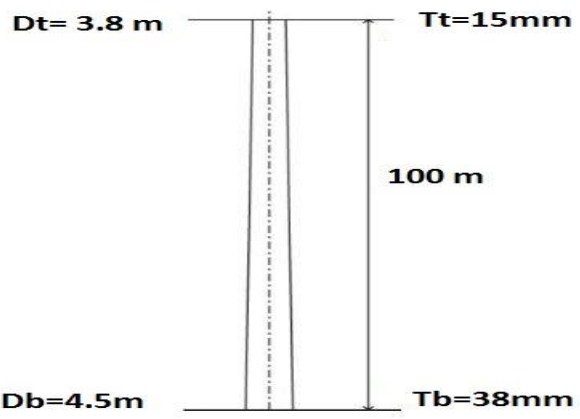

Fig -5: Tower model

Fixed boundary conditions are assumed at the lower end of the tower for all analyses. Quadrilateral tetrahedron shell elements (4-node element) are used for the tower wall. High strength structural steel grade S355 with yield stress of 355 $\mathrm{MPa}$ is used for all structures.

\section{RESULTS}

There are three cases considered

1) With uniform thickness of $38 \mathrm{~mm}$

2) With usual thickness i.e. $38 \mathrm{~mm}$ at base and $15 \mathrm{~mm}$ at the top.

3) $70 \mathrm{~mm}$ thickness at the base and $15 \mathrm{~mm}$ at the top.

For all the above cases two condition are considered i.e. wind direction on the opposite side of door opening and wind direction on the side of the door opening.

\subsection{Case 1}

The maximum stress at the door opening for the first condition is found to be $484.98 \mathrm{~N} / \mathrm{mm}^{2}$ and in the second condition i.e. wind direction was in the direction of door opening maximum stress at the door opening 452.92 $\mathrm{N} / \mathrm{mm} 2$. The maximum deformation for wind direction opposite to the door opening was about $2.61 \mathrm{~m}$ at the top and for the other condition it was $2.6 \mathrm{~m}$ so it was almost same. For the first case when wind direction was opposite to door opening the minimum cycles near the door opening was 1578.7 and in the other condition it was 2017.4

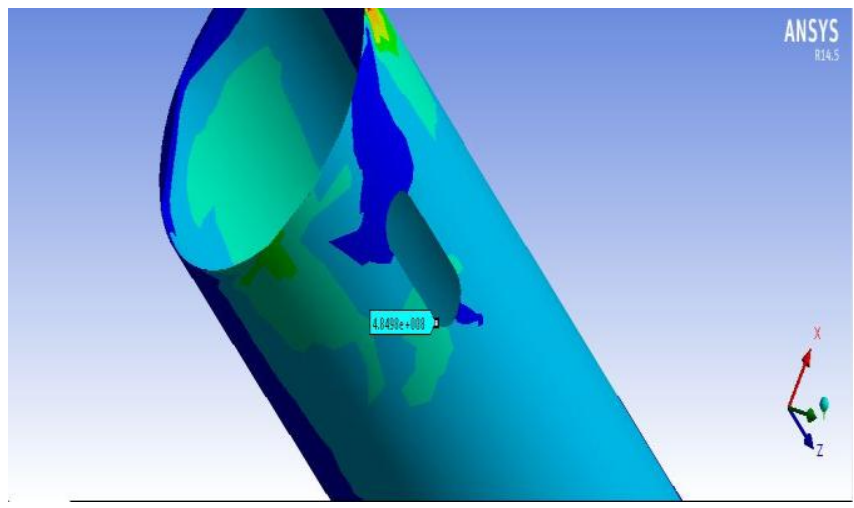

Fig -6: Stress near door opening for case 1 value shown is in $\mathrm{Pa}$.

\subsection{Case 2}

The maximum stress at the door opening for the first condition is found to be $387.09 \mathrm{~N} / \mathrm{mm}^{2}$ and in the second condition i.e. wind direction was in the direction of door opening maximum stress at the door opening 351.03 $\mathrm{N} / \mathrm{mm} 2$. The maximum deformation for wind direction opposite to the door opening was about $3.13 \mathrm{~m}$ at the top and for the other condition it was $3.127 \mathrm{~m}$ so it was almost same. For the first condition when wind direction was opposite to door opening the minimum cycles near the door opening was 2979.5 and in the other condition it was 3728.7 .

\subsection{Case 3}

In the third case the values of stress decreases considerably.

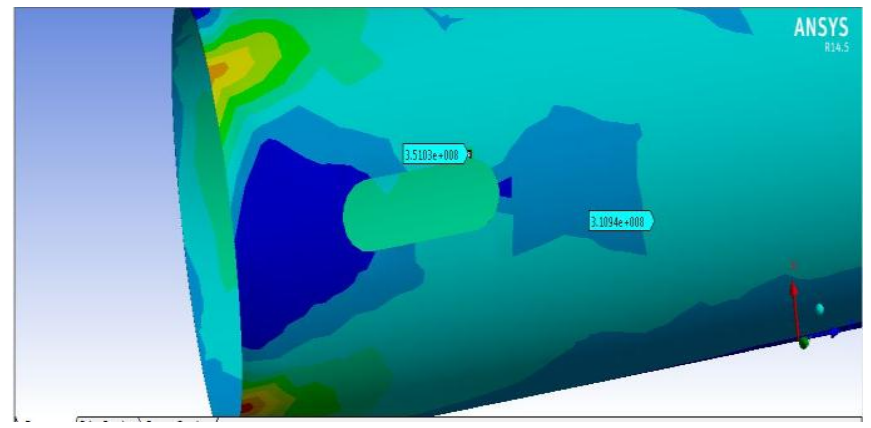

Fig -7: Stress near door opening for case 2 value shown is in $\mathrm{Pa}$. 
The maximum stress at the door opening for the first condition is found to be $251 \mathrm{~N} / \mathrm{mm} 2$ and in the second condition i.e. wind direction was in the direction of door opening maximum stress at the door opening 231.77 $\mathrm{N} / \mathrm{mm} 2$.The maximum deformation for wind direction opposite to the door opening was about $1.84 \mathrm{~m}$ at the top and for the other condition it was $1.83 \mathrm{~m}$ so it was almost same. For the first condition when wind direction was opposite to door opening the minimum cycles near the door opening was 11376 and in the other condition it was 15852 .

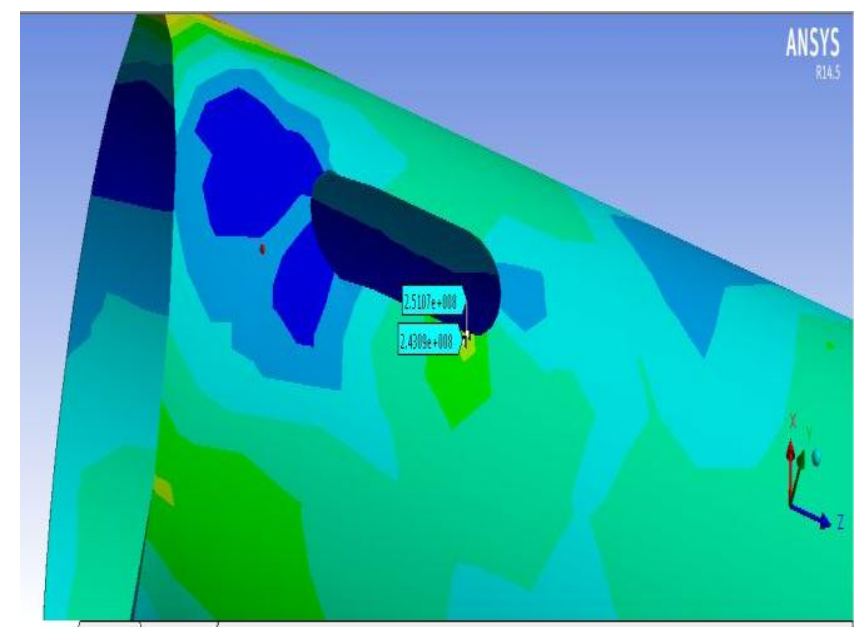

Fig -8: Stress near door opening for case 3 value shown is in $\mathrm{Pa}$.

\section{CONCLUSIONS}

Initially the wind turbine model with usual dimensions i.e. base thickness of $38 \mathrm{~mm}$ and top thickness of $15 \mathrm{~mm}$ was considered to check the stresses near the door opening and to compare it with the other options. Second model was made with uniform thickness which shows that the thickness at the upper section does not play role in the stress as well as no. of cycles of loading.

Finally to minimize the stresses near door opening it was desirable to increase the thickness of lower tower section. So $70 \mathrm{~mm}$ was chosen as new thickness and analysis was done. With the new thickness the stresses decreases considerably from $387 \mathrm{~N} / \mathrm{mm} 2$ to almost $251 \mathrm{~N} / \mathrm{mm} 2$ which shows the influence of thickness on the stresses.

Further with increased thickness the minimum no. of cycles near door opening is increased drastically from almost 2979 to 11376 which is almost 4 times the original.

One more conclusion is made with respect to direction of wind and orientation of door opening as we consider the door opening in the direction of wind then the stresses are bit of higher and no. of cycles are lesser than the condition where the door opening is in the opposite direction to the wind.

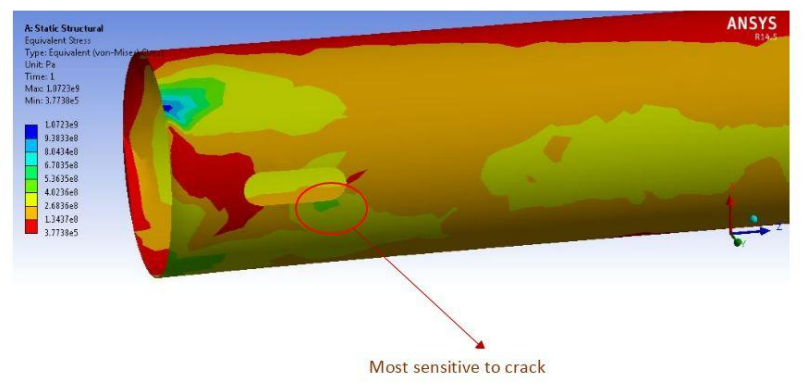

Crack may happen at the side of door where the stress is higher than the stress intensity factor of the structural steel. The probable area from where crack may happen is shown as follows. To minimize the chances of crack there is an option of increase in thickness of lower tower section which we have considered in this thesis and is having quite satisfactory results as the stress intensity factor in the $3^{\text {rd }}$ condition is lesser than the maximum stress near the door opening.

\section{REFERENCES}

[1]. Indian wind energy outlook 2012 - ministry, new and renewable energy, Government of India

[2]. 15. European Committee for Standardization. Euro code 3 - design of steel structures, Part 1 - 6: strength and stability of shell structures; 2006

[3]. IS 875 part 3, by Indian bureau of standards.

[4]. LaNier, M. P. (2005). LWST Phase I Project Conceptual Design Study: Evaluation of Design and Construction Approaches for Economical Hybrid Steel/Concrete Wind Turbine Towers. Golden: National Renewable Energy Laboratory.

[5]. Design, manufacture, transportation, and foundation construction of wind turbine towers By P. W. Magoha, Department of Mechanical Eng., Jomo Kenyatta University of Agriculture \& Technology Nairobi 00200, Kenya

[6]. Preliminary Design of 1.5-MW Modular Wind Turbine Tower Chawin Chantharasenawong*, Pattaramon Jongpradist and Sasaraj Laoharatchapruek Department of Mechanical Engineering, King Mongkut's University of Technology Thonburi, Bangkok, Thailand 10140

[7]. To study of wind resistant stability of tubular wind turbine tower By Fahad jamil, Saad bin zia, Parvez ali abbasi, Moiz Ansari, NED University of Engineering \& Technology

[8]. Status and problems of wind turbine structural health monitoring techniques in China Wenyi Liu, Baoping Tang, Yonghua Jiang, The State Key Laboratory of Mechanical Transmission, Chongqing University, Chongqing 400030, China

[9]. Resistance of door openings in towers for wind turbines By Anh Tuan Tran, Milan Veljkovic, Carlos Rebelo and Luis Simoes da Silva, Lulea University of Technology University Campus, Porson, Sweden

[10]. Structural design optimization of wind turbine towers by Hani M. Negma, Karam Y. Maalawib, Aerospace Engineering Department, Cairo University, Cairo, Egypt 
Mechanical Engineering Department, National Research Center, Cairo, Egypt

[11]. Optimization of thin wall cylindrical shell by Mathews A. Dawson 2004

[12]. ANSYS® Multiphysics. 2007. “ANSYS Element Reference." Release 11.0, Documentation for ANSYS. ANSYS Inc.

[13]. International Electrotechnical Commission (IEC). 2001. IEC System for Conformity Testing and Certification of Wind Turbines - Rules and Procedures. IEC WT 01:2001-04. IEC, Geneva, Switzerland.

[14]. International Electrotechnical Commission (IEC). 2005. Wind Turbines - Part 1: Design Requirements, 3rd Edition. IEC 61400-1:2005-08. IEC, Geneva, Switzerland.

\section{BIOGRAPHIES}

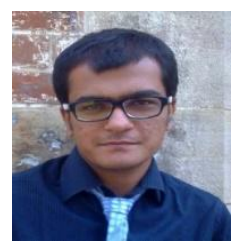

Vaghela Ajaysinh Ranjitsinh is a ME Dissertation student doing his thesis under the guidance of Dr.G.S.Doiphode from The M.S.University of Baroda. He has done his B.E. in civil engineering from the same university.

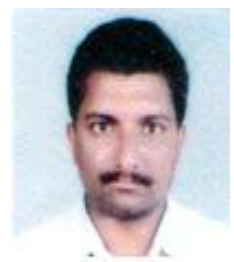

Dr.G.S.Doiphode is an assistant professor in the Faculty of Technology and Engineering, The M.S.University of Baroda. Area of Specialization : (i) Broad Area of Expertise: Structural Engineering (ii) Specific Area of Expertise: (Mention the Nature of Work like Analytical, Experimental, Computational etc.): Analysis of Structures, dynamic Analysis, (iii) Title of P.G Thesis and /or Ph D Thesis: Computer Aided Analysis, Design Drafting of Isolated Footings. 